\title{
The Effectiveness of Speed Limit Sign and Marking as the Speed Management Devices
}

\author{
Febrina Rachmatika Andini \\ Diploma IV Road Transportation Safety \\ Management \\ Road Transportation Safety Polytechnic \\ Tegal, Indonesia \\ Febrinarachmatikandini218@gmail.com
}

\author{
Pipit Rusmandani \\ Diploma IV Road Transportation \\ Safety Management \\ Road Transportation Safety \\ Polytechnic \\ Tegal, Indonesia \\ pipit@pktj.ac.id
}

\author{
Naomi Srie Kusumastutie \\ Diploma IV Road Transportation Safety \\ Management \\ Road Transportation Safety Polytechnic \\ Tegal, Indonesia \\ naomis@pktj.ac.id
}

Lovvina Arida Yusup

Diploma IV Road Transportation

Safety Management

Road Transportation Safety

Polytechnic

Tegal, Indonesia

lovvinaay37@gmail.com

\author{
Edi Purwanto \\ Diploma IV Road Transportation Safety \\ Management \\ Road Transportation Safety Polytechnic \\ Tegal, Indonesia \\ edip@pktj.ac.id
}

\begin{abstract}
Lemah Abang - Bandungan Road is an accidentprone area with high speed characteristics. In fact, there is no speed management devices available. Therefore, it is necessary to implement speed management devices with their simulations to reduce the vehicle speed. There were 2 types of devices simulated, they were the simulation of speed limit signs (simulation 1) and the simulation of speed markings (simulation 2). The effectiveness of speed management devices is based on the speed reduction according to the speed limit and the comparison of means test analysis. The results of the analysis show that the most effective speed management device is the speed limit sign from the simulation 1 because it could reduce the speed about $4 \mathrm{~km} / \mathrm{h}(7 \%)$.
\end{abstract}

Keywords: speed, speed management devices, speed limit signs, speed limit markings

\section{INTRODUCTION}

High speed causes the driver to not have enough space and time to do evasive action. It can increase the risk of accidents and fatalities. If an accident occurs at the speed of $70 \mathrm{~km} / \mathrm{h}$ the probability to cause the death toll is $83 \%$, at the speed of $50 \mathrm{~km} / \mathrm{h}$, the probability of fatal injury is $37 \%$, while at the speed of $30 \mathrm{~km} / \mathrm{h}$ the death toll decreases to $5 \%$ [1]. Speed management consists of series of actions to balance safety and to maximize compliance by reducing the high speed. Types of speed management techniques that are often applied include road design, road surfaces, traffic control and law enforcement. While speed management related to traffic control includes speed signs and markings, stop signs, warning signs, special traffic control signs, school zones, flashing signs, and signal coordination [2].

The implementation of various speed management techniques shows different results such as installing speed limit signs that can reduce speed with routine law enforcement. The application of white lane markings on both intercity and arterial roads can also reduce $85 \%$ fatality which is resulted from the speed reduction of $69-76 \mathrm{~km} / \mathrm{h}$ to
$50 \mathrm{~km} / \mathrm{h}$ [3]. Based on Parham, the application of speed limit marking is not effective enough at reducing speed although it is visible to road users [2]. In the other hand, Charlton stated that it will increase speed equality and compliance of the vehicles if the application of speed marking explains the specific speed limits [4].

The Lemah Abang - Bandungan Road in Semarang Regency is an accident-prone area [5]. The highest cause of accidents is the lack of anticipation of the drivers due to the speeding. Also, Lemah Abang - Bandungan Road does not have any speed limit signs which impact on the lack of information received by the driver and lead to driving mismatches. Based on the existing condition, the speed management devices need to be applied. The speed management devices that will be implemented on Lemah Abang - Bandungan Road include the implementation of speed limit sign (simulation 1) and the implementation speed limit marking (simulation 2). This study aims to determine the existing speed, the setting of the appropriate speed limit, and to find out the effectiveness of the speed management devices in reducing the speed on the Lemah Abang - Bandungan Road.

\section{Research Methodology}

The research location is Lemah Abang-Bandungan Road which has the function of a primary $2 / 2$ UD collector road with a road width of 6 meters and a shoulder of 1 meter. This road section has a flat alignment and land use in the form of settlements. The total number of vehicle samples calculated using the Slovin formula is 560 vehicles out of 1679 passing vehicles that pass in the direction of Lemah Abang. Meanwhile, the lane that has a higher speed characteristic is the Bandungan direction lane so that the number of samples that must be taken during simulation 1 and simulation 2 is 532 vehicles out of the total number of vehicles that pass namely 1077 vehicles. 
The speed survey is carried out in the off-peak time at 07.00 AM until 10:00 AM. This study uses the descriptive quantitative method. The first stage of the study is to conduct a preliminary survey to identify existing problems. The next stage is to collect the data. Then, the simulations were conducted by applying speed limit sign (simulation 1) and speed limit marking (simulation 2) for seven days of each. The procedure for setting the speed limit based on Regulation of Minister of Transportation of Republic of Indonesia Number PM 111 of 2015 is $40 \mathrm{~km} / \mathrm{h}$ [6].

The speed was measured on three different areas: before the simulation area, at the simulation area, and after passing the simulation area. Each of area is 50 meters long. For data analysis, this study used the Percentil-85 (P-85) technique and the comparison of means test analysis. Meanwhile, the effectiveness of speed limit signs and markings is determined by the results of the speed reduction. Fig. 1 shows the research flow chart.

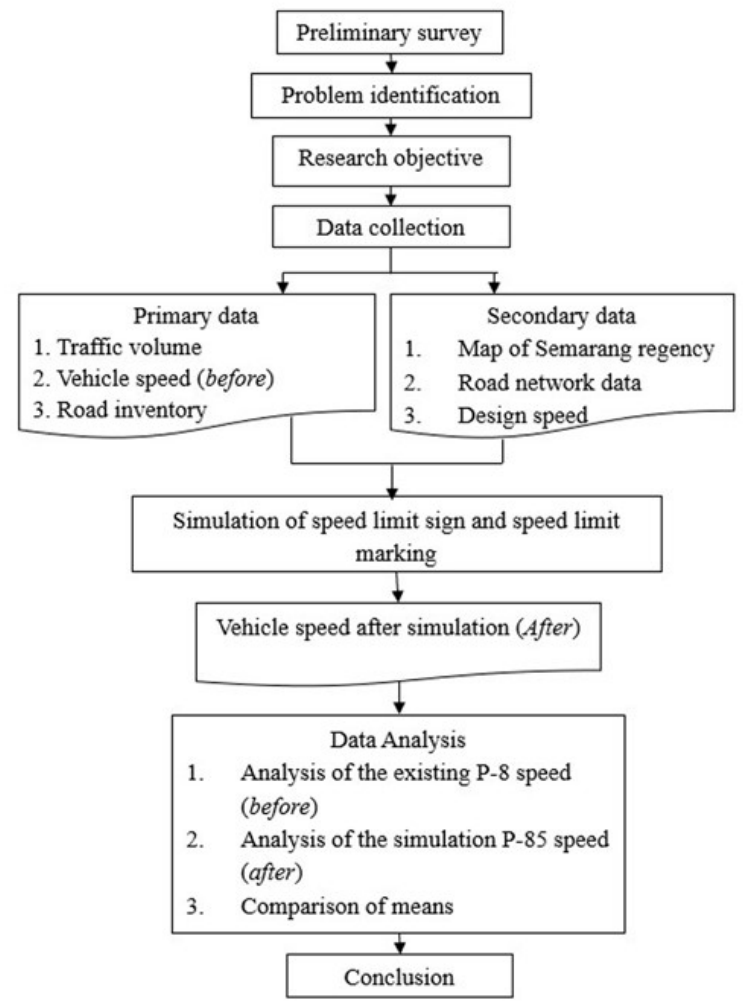

Fig. 1. Research flow chart.

\section{RESULTS}

\section{A. Vehicle Existing Speed}

Based on the results of the existing speed survey, the speed of vehicles passing in the direction of Bandungan is higher than the vehicles passing in the direction of Lemah Abang. The existing P-85 speed of all vehicles in Bandungan direction is $61 \mathrm{~km} / \mathrm{h}$ and the P-85 speed of all existing vehicles in Lemah Abang direction is $60 \mathrm{~km} / \mathrm{h}$. In detail, the vehicle's existing speed is shown in Fig. 2 below.

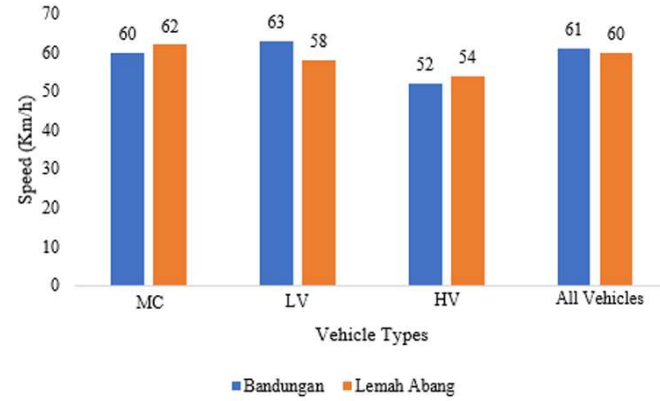

Fig. 2. The existing P-85 speed of Lemah Abang-Bandungan Road.

\section{B. The Location and Design of the Speed Management Device Installation}

The location of the speed management device installation is determined based on the characteristics of the higher speed, the requirements of speed management device and the potential risk for each lane. Based on the preliminary survey, the lane in Bandungan direction is determined as the location of simulation because it has higher speed. Furthermore, there is an elementary school (Bergas Lor 2 National Elementary School) where many students tend to use the road shoulder. So, the speed reduction is needed as the safety improvement.

In simulation 1, the installation of the speed limit sign is based on the Regulation of the Regulation of Minister of Transportation of Republic of Indonesia Number PM 13 of 2014 on Traffic Sign: it must be installed on the shoulder of the road with a distance of 0.6 meters from the roadway facing the arrival of the traffic direction and it must be placed at the beginning of the prohibition [7]. The height is 2.5 meters and the leaf sign is $60 \mathrm{~cm} \times 60 \mathrm{~cm}$. It is designed for the designed speed of up to $60 \mathrm{~km} / \mathrm{h}$. Fig. 3 shows visualization of simulation 1 .

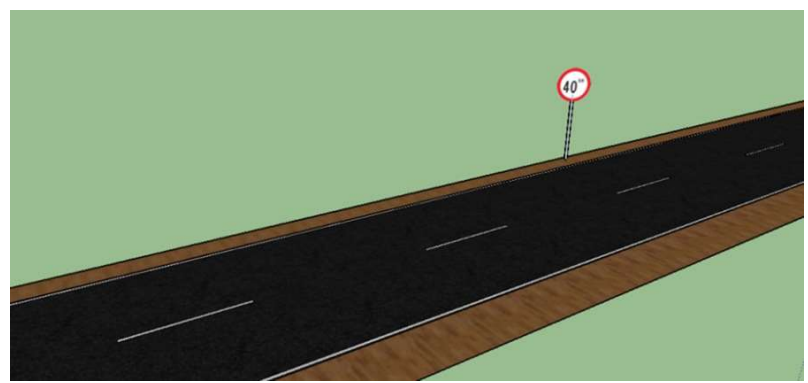

Fig. 3. Visualization of Simulation 1: Speed Limit Signs.

In simulation 2, the installation of the speed limit marking is based on the Regulation of Minister of Transportation of Republic of Indonesia Number PM 67 of 2018 on Road Markings [8]. The speed limit marking can be placed individually or with certain traffic signs. In simulation 2, the speed limit marking is in the middle of the traffic lane in the direction of Bandungan. The size of the extended speed limit marking for the designed speed $\leq 65$ $\mathrm{km} / \mathrm{h}$ has a length of 4.3 meters and a width of 1.5 meters where the extended letters have a size of 1.6 meters [9]. Fig. 4 shows visualization of simulation 2 . 


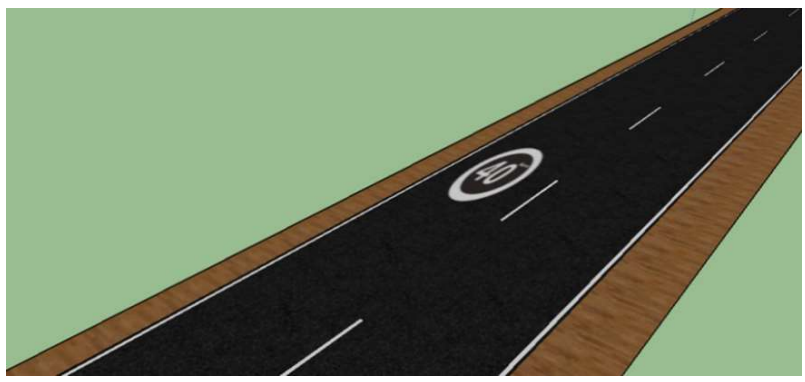

Fig. 4. Visualization of Simulation 2: Speed Limit Markings.

\section{Vehicles Speed during the Simulations}

Based on Fig. 5, it can be seen that the installation of simulation 1 causes the P-85 speed that fluctuated every day. On the $7^{\text {th }}$ day, it showed the speed reduction of motor cycle (MC) from $60 \mathrm{~km} / \mathrm{h}$ to $57 \mathrm{~km} / \mathrm{h}$, Light Vehicle (LV) decreased from $63 \mathrm{~km} / \mathrm{h}$ to $58 \mathrm{~km} / \mathrm{h}$ while Heavy Vehicles increased from $52 \mathrm{~km} \mathrm{~h}$ to $54 \mathrm{~km} / \mathrm{h}$. The existing P-85 speed of all vehicles decreased from $61 \mathrm{~km} / \mathrm{h}$ to $57 \mathrm{~km} / \mathrm{h}$.

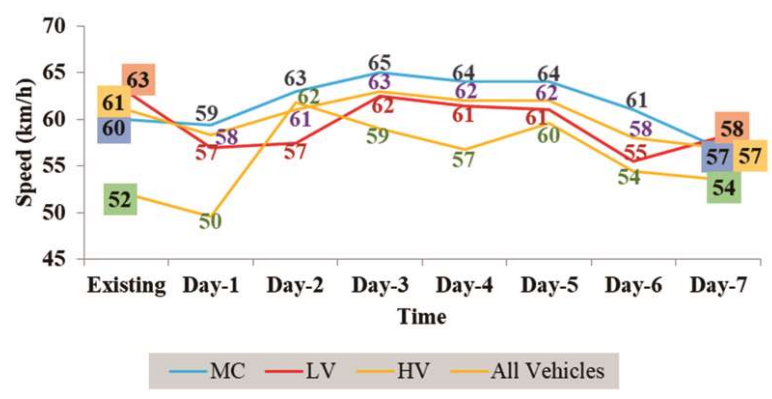

Fig. 5. The Comparison of P-85 Speed Before and After Simulation 1.

Based on Fig. 6, it can be seen that the installation of simulation 2 causes the P-85 speed that fluctuated every day. On the $7^{\text {th }}$ day, it showed the speed reduction of motor cycle (MC) from $60 \mathrm{~km} / \mathrm{h}$ to $59 \mathrm{~km} / \mathrm{h}$. Light Vehicle (LV) decreased from $63 \mathrm{~km} / \mathrm{h}$ to $57 \mathrm{~km} / \mathrm{h}$ while the speed of Heavy Vehicles (HV) didn't show any difference (still 52 $\mathrm{km} / \mathrm{h}$ ). The speed of all vehicles decreased from $61 \mathrm{~km} / \mathrm{h}$ to $58 \mathrm{~km} / \mathrm{h}$.

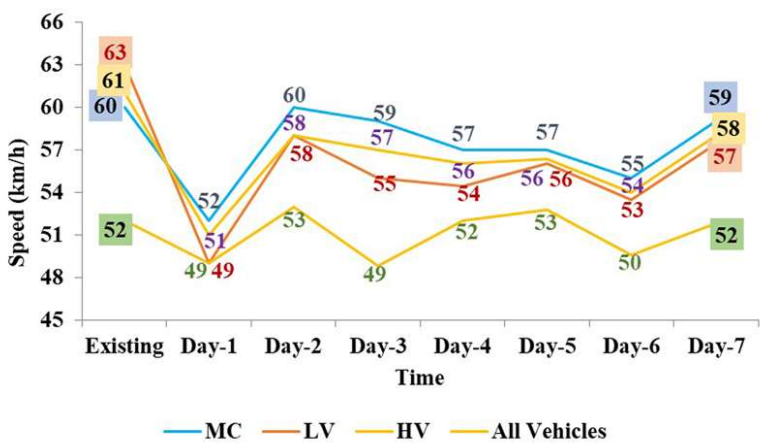

Fig. 6. P-85 Speed Comparison of Existing Speed and After Simulation 2.

\section{The Comparison of the Speed in both Simulation 1 and Simulation 2}

Based on the results above, both simulation 1 and simulation 2 experienced the speed reduction. Fig. 7 shows most vehicles reduced their speed but it had not reached the target yet of $40 \mathrm{~km} / \mathrm{h}$. Simulation 1 could reduce the P-85 speed by $7 \%$ or $4 \mathrm{~km} /$ hour. While simulation 2 only reduced the P-85 speed of all vehicles by $5 \%$ or $3 \mathrm{~km} /$ hour. Fig. 7 shows comparison of P-85 speed ini simulation 1 and simulation 2 .

Fig. 8 shows a comparison of the P-85 speed of each simulation area. All vehicles tends to reduce their speed only when they passed the simulation area. Their speed tends to increase after passing it.

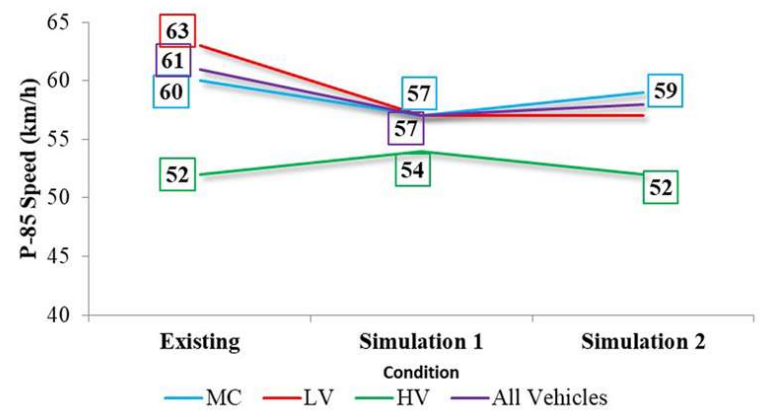

Fig. 7. Comparison of P-85 Speed in Simulation 1 and Simulation 2.

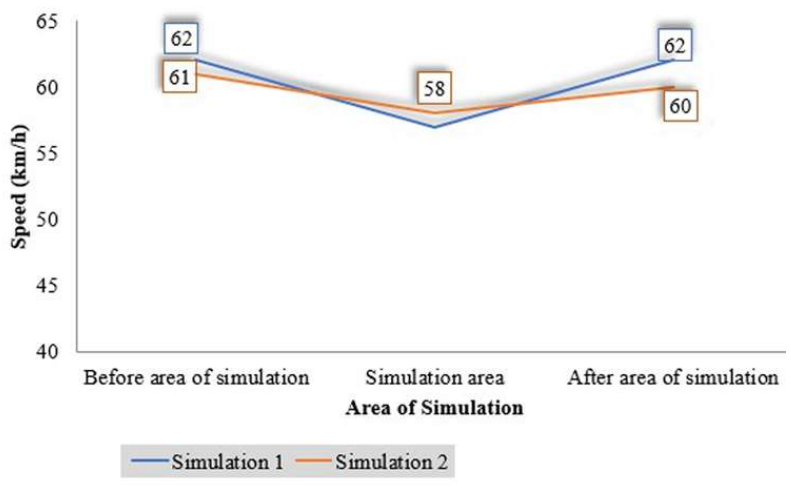

Fig. 8. Comparison of P-85 Speed in Simulation 1 and Simulation 2.

\section{E. Comparison of Means Test}

The study uses Kruskal Wallis Test for the Comparison Means Test because the normality and homogeneity requirements are not fulfilled. The result of Kruskal Wallis test shows the speed differences, i.e. reduction, of MC, LV, and all vehicles before and after simulations (Asymp. Sig. < 0.05). However, there is no difference of the HV speed during the simulations 1 and 2 because the significance value (Asymp. Sig.) $>0.05$. TABLE I shows the comparison means test before and after simulation 1 and simulation 2 .

TABLE I. COMPARISON MEANS TEST BEFORE AND AFTER SiMULATION 1 AND SiMULATION 2

\begin{tabular}{|l|l|l|l|l|l|}
\hline No & $\begin{array}{c}\text { Vehicle } \\
\text { Type }\end{array}$ & \multicolumn{1}{|c|}{ N } & Mean & \multicolumn{1}{|c|}{$\begin{array}{c}\text { Asymp Sig. } \\
\text { Value }\end{array}$} & Criteria \\
\hline 1 & MC & 265 & 47 & 0.000 & Reject $\mathrm{H}_{0}$ \\
\hline 2 & LV & 238 & 47 & 0.000 & Reject $\mathrm{H}_{0}$ \\
\hline 3 & HV & 29 & 43 & 0.465 & Accept $\mathrm{H}_{0}$ \\
\hline 4 & $\begin{array}{l}\text { All } \\
\text { Vehicles }\end{array}$ & 532 & 47 & 0.000 & Reject $\mathrm{H}_{0}$ \\
\hline
\end{tabular}


The next step is to do the post hoc test which uses the Mann Whitney U Test. This test is done since the KruskalWallis test cannot explain which simulation that is able to reduce the speed significantly. The Mann Whitney $U$ test is a nonparametric test of the null hypothesis that it is equally likely that a randomly selected value from one sample will be less than or greater than a randomly selected value from a second sample. This test can be used to investigate whether two independent samples were selected from populations having the same distribution.

TABLE II. Mann Whitney Test on All Vehicle Speed

\begin{tabular}{|l|l|l|l|}
\hline No & Mann-Whitney Test & \multicolumn{1}{|c|}{ Mean Rank } & \multirow{2}{*}{ Asymp. Sig } \\
\hline 1 & Existing & 575.12 & \multirow{2}{*}{0.000} \\
\hline 2 & Simulation 1 & 489.88 & \\
\hline 3 & Existing & 546.92 & \multirow{2}{*}{0.126} \\
\hline 4 & Simulation 2 & 518.08 & \\
\hline
\end{tabular}

In the Mann Whitney test, the first thing to consider in finding the group that have significant differences is the mean rank. The difference of the values can be considered significant if the Asymp. Sig $<0.05$. TABLE II shows the speed of simulation 1 has the lowest rating, i.e. 0.000 Asymp. Sig. So it can be concluded that the simulation 1 can reduce the speed significantly.

\section{DISCUSSIONS}

The implementation of the speed limit signs (simulation 1) can reduce the speed but it will increase again when the sign is absent or lacking repetition [10]. It is evident that speed limit sign can reduce the speed of all vehicles by $7 \%$ or $4 \mathrm{~km} / \mathrm{h}$. It is more effective to reduce the speed of the all vehicles than the use of speed limit marking which is only $5 \%$ or $3 \mathrm{~km} / \mathrm{h}$ (simulation 2 ).

The implementation of the speed limit marking (simulation 2) is new to Indonesian people because it does not yet exist in Indonesia. The information conveyed by the speed limit marking do not reach the road users even though its aspect of conspicuity and clearance have been fulfilled. This is supported by the FHWA Report: Traffic Calming on Main Roads through Rural Communities shows that the installation of oblique markers combined with speed limit markings that are installed for 12 months is not effective in reducing speed because it only reduces the speed of $1 \mathrm{~km} / \mathrm{h}$ to $4 \mathrm{~km} / \mathrm{h}$ [11].

The most effective speed management device to reduce the speed of all vehicles on Lemah Abang - Bandungan Road is the speed limit sign. This device can decrease the speed even though it has not approached the speed limit yet. The speed reduction is proven most significantly by the Mann-Whitney test.

Based on the description above, even though the speed limit has been set and the sign and marking devices have been installed, the speed reduction is still temporary and it has not reached the speed limit yet. Thus, the challenge faced is the speed management must be able to improve the road users' understanding about the speed limit and safety awareness. Therefore, the socialization of speed limit sign and marking is needed to follow up the installation of speed management devices.

\section{CONCLUSIONS}

P-85 speed of Bandungan for MC is $60 \mathrm{~km} / \mathrm{h}, \mathrm{LV} 63$ $\mathrm{km} / \mathrm{h}, \mathrm{HV} 54 \mathrm{~km} / \mathrm{h}$, and the speed of the whole vehicles is $61 \mathrm{~km} / \mathrm{h}$. P-85 speed of Lemah Abang is $62 \mathrm{~km} / \mathrm{h}$ by MC, LV $58 \mathrm{~km} / \mathrm{h}, \mathrm{HV} 42 \mathrm{~km} / \mathrm{h}$, and the speed of all vehicles is $60 \mathrm{~km} / \mathrm{h}$. The suitable speed limit for Lemah Abang Bandungan Road is $40 \mathrm{~km} / \mathrm{h}$ because it is a primary collector road. It does not have a fast lane and slow lane. The land use of this road is a dense residential area.

The installation of speed limit sign (simulation 1) decreases the speed of P-85 for all vehicles by $7 \%$ or 4 $\mathrm{km} / \mathrm{h}$. the installation of speed limit marking (simulation 2) decreases the speed of P-85 for all vehicles by $5 \%$ or 3 $\mathrm{km} / \mathrm{h}$. The comparison of means test results using the Kruskal Wallis test shows that there is a significant difference between the before and after speed of MC, LV, and all vehicles in simulation 1 and simulation 2 . It can be determined from the value of Asymp. Sig $<0.05$. The Mann Whitney $U$ test shows that the simulation 1 reduces most speed significantly since it has the lowest mean rank and Asymp. Sig value $<0.05$.

\section{ACKNOWLEDGMENT}

The writers would like to thank Allah SWT for providing convenience in the preparation of this study. The writers also thank the Lecturers who have guided. For the last, the writers thank the Transportation Agency of Semarang that helps the research process.

\section{REFERENCES}

[1] M. Bell et al., "Transport planning and traffic enginering." Amsterdam: Elsevier, 1997.

[2] A. H. Parham dan K. Fitzpatrick, "Handbook of speed management techniques." Texas Transportation Institute, Texas, 1998.

[3] L. Herrstedt, "Self-explaining and forgiving roads - Speed management in rural areas," in ARRB Conference, 2006.

[4] Semarang Regency Professional Work Practices Team, "Professional work practices report: Semarang Regency road transportation safety performance book", unpublished.

[5] S. G. Charlton, N. J. Starkey, dan N. Malhotra, "Using road markings as a continuous cue for speed choice," Accid. Anal. Prev., vol. 117, no. April, p. 288-297, 2018.

[6] Regulation of Minister of Transportation of Republic of Indonesia Number PM 111 of 2015 on Procedures for Setting Speed Limits.

[7] Regulation of Minister of Transportation of Republic of Indonesia Number PM 13 of 2014 on Traffic Sign.

[8] Regulation of Minister of Transportation of Republic of Indonesia Number PM 67 of 2018 on Road Markings.

[9] The Department for Transport, "Traffic signs manual - chapter 5 road markings." The Department for Transport, London, 2019.

[10] E. M. M. Jongen, K. Brijs, K. Mollu, T. Brijs, dan G. Wets, "70 km/h speed limits on former $90 \mathrm{~km} / \mathrm{h}$ roads: Effects of sign repetition and distraction on speed," Hum. Factors, vol. 53, no. 6, p. 771-785, 2011.

[11] Federal Highway Administration, "Tech brieft: traffic calming on main roads through rural communities." U.S. Departement of Transportation Federal Highway Administration, McLean, 2009. 